\title{
Production of Antibodies in Chicken for Escherichia Coli O157:H7
}

\author{
Priyanka B ${ }^{1}$, Rajashekhar K Patil ${ }^{2}$, Sulatha Dwarakanath ${ }^{3}$ \\ ${ }^{1,2}$ (Department of Applied Zoology, Mangalore University, Mangalagangothri - 574199 Karnataka, India) \\ ${ }^{3}$ (Nano Science Diagnostics, Austin, Texas - 78726, United States of America)
}

\begin{abstract}
Escherichia coli serotype $\mathrm{O} 157: \mathrm{H7}$ is a Gram-negative rod-shaped bacterium. Despite the availability of potent antibiotics, Gram negative bacteraemia and sepsis is currently a frequent cause of death in hospitals. Chicken egg yolk can become an important tool here.

Biochemical tests, comparative studies of $\mathrm{pH}$, temperature and media were conducted to pick out the right strain of bacteria. IgY was produced and isolated from yolk using three different protocols to get the highest yield on production. The final product was tested by methods like ELISA, dot blotting and SDS-PAGE. The antibody was purified by affinity chromatography. It was found that the serotype being used was pure and not contaminated. The IgY produced from PEG ethanol method was found to give the best results.

This method makes it easy to produce the antibody in bulk, which in turn will help diagnose the symptoms caused by Escherichia coli O157:H7 far more rapidly than other methods. Further the antibody can be formulated for therapeutic uses.
\end{abstract}

Keywords: Chicken IgY, diagnostics use, Escherichia coli O157:H7, PEG ethanol method.

\section{Introduction}

Escherichia coli were discovered by German pediatrician and bacteriologist Theodor Escherich in 1885. Escherichia coli serotype O157:H7 is a Gram-negative rod-shaped bacterium. This is confirmed by Gram staining and biochemical tests like IMViC. The Escherichia coli O157:H7 was confirmed by growing them on the Mac Conkey media. Escherichia coli have genetically and phenotypically diverse groups, which can be identified on the basis of basically three types of antigens. These are somatic $\mathrm{O}$ antigen, flagellar $\mathrm{H}$ and fimbrial $\mathrm{K}$ antigen [1,2]. However the strains are generally referred in the ratio of $\mathrm{O}: \mathrm{H}$. Escherichia coli O157:H7 was first identified as a human pathogen and the cause of hemorrhagic colitis in the United States in 1982. Many cases of outbreaks of hemorrhagic colitis and hemolytic uremic syndrome have been associated with Escherichia coli O157:H7 infections [3,1]. Escherichia coli O157:H7 is an enterohemorrhagic strain of the bacterium Escherichia coli and a cause of foodborne illness. Infection often leads to bloody diarrhea, and occasionally to kidney failure, especially in young children and elderly people. Most illness has been associated with eating undercooked, contaminated ground beef, drinking unpasteurized milk, swimming in or drinking contaminated water, and eating contaminated vegetables [4]. Despite the availability of potent antibiotics, Gram negative bacteraemia and sepsis is currently a frequent cause of deaths in hospitals. The development of vaccines against the most common Gram-negative sepsis causing bacteria (e.g., Escherichia coli) or of antibodies for passive immunization is therefore an important objective [5]. It is always said that the use of antibiotics eliminates commensal (normal flora) bacteria. In order to save the normal flora being targeted for the antibiotics, the need for research towards developing vaccines or antibiotics is important.

When it comes to production of the antibodies, it is very important that it is produced in large amount and also in an easy method. The most common method is to isolate the lipopolysaccharide (LPS) and then inject them to mammals, mostly rabbit, and the antibodies are then isolated from its serum. In mammals the antibodies are produced as IgG. But some of the drawbacks include frequent drawing of blood which is painful for the animals [6]. Another drawback is production of lesser amount of $\mathrm{IgG}$ [7]. Also antibodies that are produced in the serum of mammals have phylogenetic similarity when it is tested on humans and hence will activate complement system when actually not applicable and hence will lead to false positive results. Chicken egg yolk becomes an alternative in order to overcome the above mentioned obstacle [8]. To produce the antibodies, whole cell antigens are injected into the chickens. After two booster doses, the eggs are collected. Here the yolk is separated from the albumin. This yolk has IgY for the antigen injected. IgY is nothing but IgG. Since it is produced in yolk, it is given the name IgY to differetiate it from the antibody produced in mammals.

IgY is isolated and its concentration is measured. This is higher than that in the serum [9, 7]. Protein estimation of the isolated IgY was done by Lowry's method. Affinity chromatography was done to get the specific antibody. Affinity chromatography, developed in the 1960s and 1970s, is a technique where a ligand is used to interact with the protein. This helps to separate the protein of interest from other proteins. The basic principle of affinity adsorption chromatography is that a ligand is covalently attached to the backbone of the 
matrix. Only specific enzymes with specific affinity for the ligand can bind to the adsorbent. Remaining protein will pass through the column unaffected [10].

In this experiment, a comparative study was made between three methods of isolation, the conventional method, Pierce kit and Polyethylene glycol (PEG) ethanol method.

\subsection{Biochemical tests}

\section{Materials And Methods}

A loopful of Escherichia coli O157:H7 from the glycerol stock was inoculated into the fresh Tryptic Soy Broth (TSB) (MP Biomedicals cat.no. 157152) (pH 7.2). For this first the Gram staining (Carolina cat. no. 154724) and then the Indole test, Methyl Red test, Voges-Proskaeur test and Citrate test, shortly called as IMViC test was performed as done in all the microbiological studies. After all this the organism was grown on the Mac Conkey agar (Sigma-Aldrich cat no. M7408].

\subsection{Growth Kinetics}

Growth kinetics included the study of growth curve and growth kinetics with different concentrations of the culture. Esherischia coli O157:H7 was grown overnight. For this 50ml of Tryptic Soy Broth (TSB) (MP Biomedicals cat.no. 157152) ( $\mathrm{pH}$ 7.2) was taken and to this, a colony from the plate was inoculated and mixed well. This was grown at $37^{\circ} \mathrm{C}$ overnight in $4 \mathrm{ml} \mathrm{TSB}$ media. The following day $1 \mathrm{ml}$ of this culture was taken and OD was measured at $540 \mathrm{~nm}$ on a spectrophotometer and this reading was noted down as $0^{\text {th }} \mathrm{hr} .1 \mathrm{ml}$ of the culture was taken in a microfuge tube and spun down the culture at 5000rpm. The supernatant was discarded and the pellet was kept for air drying. This was for the dry weight method. Same procedure was followed for every one hour up to 18 hours. A graph was plotted with time against OD for turbidometric method and with time against weight. All procedures were done in duplicates.

The experiment performed for generation time was initially tried with the undiluted, overnight grown culture. This experiment is where the effort was made to know what will be the possible result when the plating of the culture will be undiluted, 1:1,1:10 and 1:100 dilutions. The protocol for the generation time was followed according to the one that is mentioned above. Each dilution at every two hour interval was plated on a fresh Tryptic Soy Agar (TSA) plate and incubated at $37^{\circ} \mathrm{C}$ overnight. This experiment was performed in duplicates. Also it must be noted that the plating was done up to 12 hour and last reading was taken at 24 hour from the same culture.

\section{$2.3 \mathrm{pH}$ experiment}

Esherischia coli $\mathrm{O} 157: \mathrm{H} 7$ was grown in the desired media overnight at $37^{\circ} \mathrm{C}$. The media was adjusted to different $\mathrm{pH}$ values. The range considered here was from $\mathrm{pH} 3.0$ to 9.0. The culture was inoculated into each of the tubes using a sterile inoculation loop. Each tube had $4 \mathrm{ml}$ of the TSB media. The tubes were incubated overnight at $37^{\circ} \mathrm{C}$. All the cultures were plated on Tryptic Soy Agar (TSA). All the plates were incubated overnight at $37^{\circ} \mathrm{C}$. Plates were checked for growth and photographed. All tests were done in triplicates.

\subsection{Temperature experiment}

Esherischia coli $\mathrm{O} 157: \mathrm{H} 7$ was grown overnight at $37^{\circ} \mathrm{C}$. The media were adjusted to different temperature values. The temperatures considered were $0^{\circ} \mathrm{C}, 25^{\circ} \mathrm{C}, 37^{\circ} \mathrm{C}, 45^{\circ} \mathrm{C}, 65^{\circ} \mathrm{C}$ and $75^{\circ} \mathrm{C}$. The culture was inoculated into each of the tubes using a sterile inoculation loop. Each tube had $4 \mathrm{ml}$ of the TSB media. Overnight incubation was done at $37^{\circ} \mathrm{C}$. All the cultures were plated onto TSA plates and incubated overnight at $37^{\circ} \mathrm{C}$. Plates were checked for growth and photographed. All the experiments were done in triplicates.

\subsection{Media experiment}

$4 \mathrm{ml}$ each of the following media-Tryptic Soy Broth (TSB), Mueller-Hinton Broth (MHB) (BD cat.no. 70192), Luria-Bertani Broth (LB) (Fluka Biochemicals cat. no. L3022), TSB enriched with yeast extract (BD cat.no. 212750), peptone and sodium chloride (Fisher cat.no. S78446), TSB (autoclaved once) and TSB (autoclaved twice) were taken in different tubes. A loopful of overnight grown culture Esherischia coli O157:H7 was inoculated into each media. Different loops were used for different media. All were incubated at $37^{\circ} \mathrm{C}$ overnight. Observation was done the next day.

\subsection{Antibiotics experiment}

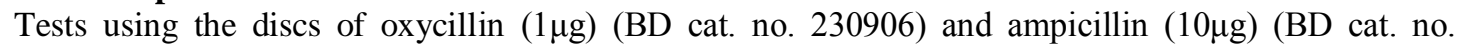
A9518) were done to determine whether the antibiotics were able to kill the bacteria. For this a loopful of overnight grown culture was spread evenly on a TSA plate. It was allowed to dry for a few seconds after which the discs were placed at the centre of plate and was incubated overnight at $37^{\circ} \mathrm{C}$. The results were observed the following day and the pictures of these plates were taken. 


\subsection{Preparation of antigens of Escherischia coli O157:H7}

Escherischia coli $\mathrm{O} 157: \mathrm{H7}$ was grown in the Nutrient Broth (NB) for 18 hours at $37^{\circ} \mathrm{C}$. The suspension was sedimented at $3000 \mathrm{Xg}$ for $15 \mathrm{~min}$ and resuspended in Phosphate Buffer Saline (PBS) (ICN Biomedicals cat.no. 2810305). Flagella was removed by homogenization of the bacterial suspension in a mechanical blender for $1 \mathrm{~min}$. The bacterial cells were removed by centrifugation at $3000 \mathrm{Xg}$. Flagella were then sedimented by high speed centrifugation, then acid treated and precipitated with ammonium sulphate. Finally the pellet was resuspended in distilled water and stored at $-20^{\circ} \mathrm{C}$. To inject this to the chickens the suspension was thawed. It was then taken in a syringe and was injected in the wings and the breast region of the chickens. This was considered as Day 1. A fortnight after this the same protocol was followed. This was called Booster Dose 1. Similarly Booster Dose 2 was given after another fortnight. Twenty-one days after the second booster the eggs were collected and were used for isolation of IgY. All the eggs laid before this day were discarded.

\subsection{Isolation of IgY of Escherischia coli 0157:H7 from Chicken eggs}

Three methods were used here which include conventional method, using Pierce kit and polyethylene glycol (PEG)-ethanol method. A comparative study was made between these three methods to know which method gives the best result. Before the isolation of $\operatorname{IgY}$ there is a need of preparation of antigen. This was inoculated to the chicken.

\subsubsection{Conventional method}

The yolk was separated from the albumin. The yolk sac was disrupted and the contents were collected into a measuring cylinder and final volume was determined. $3 \mathrm{mM} \mathrm{HCl}$ was added to yolk fluid at $15 \mathrm{ml} / 3 \mathrm{ml}$ of yolk fluid and $\mathrm{pH}$ was adjusted to 5 by adding $10 \%$ acetic acid. The suspension was incubated at $4^{\circ} \mathrm{C}$ for 3 hours and the suspension was centrifuged at $4^{\circ} \mathrm{C}$. Chloroform was added in equal volume to the supernatant and was incubated at $4^{\circ} \mathrm{C}$ for 12 hours (chloroform was added by continuous stirring of the supernatant). The supernatant was collected by centrifugation at $2000 \mathrm{Xg}$ for 15 minutes at $4^{\circ} \mathrm{C}$ and the supernatant was measured and ammonium sulfate was added to supernatant at $2.6 \mathrm{~g} / 13 \mathrm{ml}(20 \%)$ slowly with constant stirring. The precipitate was collected by centrifugation and dissolved in $4 \mathrm{ml}$ Tris Buffered Saline (TBS) and a pinch of Sodium azide was added and stored at $4^{\circ} \mathrm{C}$.

2.8.2 Isolation using Pierce Kit (Thermo Scientific cat. no. 44922) - Isolation was done according to the method described in the kit manual.

\subsubsection{Polyethylene glycol (PEG) ethanol method}

The eggs from immunized birds were taken and the egg yolks were separated from their associated whites using an egg separator. The yolk sac was disrupted and the contents were collected into a measuring cylinder and final volume was determined. The yolk fluid volume was diluted with four volumes of Phosphate buffer saline (ICN Biomedicals Inc. cat. no. 2810305) and was stirred continuously with the addition of $17 \%$ PEG 6000 (Fisher Scientific cat. no. W04499). The suspension was centrifuged at $6000 \mathrm{Xg}$ for $15 \mathrm{~min}$ at room temperature. The supernatant was filtered and the filtrate was stirred with the addition of $12 \%$ PEG 6000. The suspension was centrifuged at $10,000 \mathrm{rpm}$ for $15 \mathrm{~min}$ at $4^{\circ} \mathrm{C}$. The pellet was suspended in chilled ethanol (Fisher A407-4) and PBS, and centrifuged at 10,000rpm for $15 \mathrm{~min}$ at $4^{\circ} \mathrm{C}$. The final pellet obtained was dissolved in PBS(for $10 \mathrm{ml}$ of yolk fluid, pellet obtained was dissolved in $2.5 \mathrm{ml}$ PBS). The IgY was stored at $-20^{\circ} \mathrm{C}$ with the addition of $100 \mathrm{mM}$ Phenylmethanesulphonylfluoride (PMSF) and $0.02 \%$ sodium azide as preservative. Protein estimations of IgY isolated from all three methods were based on the Lowry's method protocol.

\subsection{Detection of IgY \\ 2.9.1 Dot Blotting}

A strip of Nitrocellulose membrane (Sigma cat. no. N8267) was cut and boiled in 30ml Transfer buffer (Tris $50 \mathrm{mM}$, Glycine $380 \mathrm{mM}$, SDS $0.1 \%$, methanol $20 \%$ ) for five minutes. Antigen samples were spotted separately on the nitrocellulose membrane and allowed to dry completely. Negative control (PBS) was also spotted as a separate spot. Order of spotting of samples was noted. Then the strip was transferred to blocking buffer (7\% milk powder $+0.2 \%$ Tween 20 in PBS) and incubated at room temperature for one hour. Later the strip was washed in washing buffer (Sterile PBS $+0.2 \%$ Tween 20) four times. This was transferred to a petri plate containing the appropriate antibody. Conjugating reagent (Horse Radish Peroxidase) was added which was mixed with $0.1 \mathrm{M} \mathrm{NaHCO} 3(\mathrm{pH} 8.3)$. This was incubated for one hour with gentle rocking at room temperature. Appropriate substrate was added (Tetra Methyl Benzidine- $\mathrm{H}_{2} \mathrm{O}_{2}$ or TMB- $\mathrm{H}_{2} \mathrm{O}_{2}$ for Horse Radish Peroxidase) and was incubated at room temperature for ten minutes. The strip was taken out dried and examined for development of colour in the region of spotting (Purple in case of HRP-TMB- $\mathrm{H}_{2} \mathrm{O}_{2}$ ). This was tested for the dilutions from undiluted to $1: 10,000$ 


\subsubsection{Enzyme Linked Immunosorbent Assay (ELISA)}

ELISA plates (Fisher Scientific cat. no. 15041) were coated with $100 \mu \mathrm{l}$ of cell lysate at the concentration of $1 \mathrm{mg} / \mathrm{ml}$ (dilutions to be made in $0.1 \mathrm{M}$ sodium bicarbonate buffer $\mathrm{pH}-8.3$ ). The plate was incubated at $4^{\circ} \mathrm{C}$ overnight. The plate was blocked using blocking buffer (PBS pH-7.4 + 0.02\% Tween $20+7 \%$ milk powder). The plate was incubated at $4^{\circ} \mathrm{C}$ overnight. The plate was washed with washing buffer (PBS + $0.02 \%$ Tween 20) four times. $100 \mu$ l of chicken antibodies specific to the cell lysate was added at different concentrations. The plate was incubated at $37^{\circ} \mathrm{C}$ for one hour. The plate was washed with washing buffer (PBS $+0.02 \%$ Tween 20) four times. 100 $\mu$ l of anti-chicken-Alkaline phosphatase conjugate (Sigma Aldrich cat. no. A9171) was added at appropriate dilutions (dilutions to be made in $0.1 \mathrm{M}$ sodium bicarbonate buffer $\mathrm{pH}-8.3$ ). The plate was washed with washing buffer (PBS $+0.02 \%$ Tween 20 ) four times. The plate was washed twice with $10 \mathrm{mM}$ diethanolamine ( $\mathrm{pH} 9.5$ ). $100 \mu \mathrm{l}$ of substrate para nitro phenyl phosphate (NEB cat. no. P0757) at the concentration of $1 \mathrm{mg} / \mathrm{ml}$ prepared in $10 \mathrm{mM}$ diethanolamine $(\mathrm{pH} \mathrm{9.5)}$ was added. The plate was incubated at $37^{\circ} \mathrm{C}$ for $30 \mathrm{~min}$. The readings were taken at $405 \mathrm{~nm}$ in the ELISA reader.

\subsubsection{Sodium Dodecyl Sulphate-Polyacrylamide Gel Electrophoresis (SDS-PAGE)}

For SDS-PAGE the tank was set up in the usual pattern. Protein samples mixed with the tracking dye were loaded in the wells and loading order was noted down. The gel used was Precast gels (Biorad cat. no. 4561046). Electrodes in the buffer reservoirs were connected to a DC supply (care was taken to maintain the appropriate polarity). Samples were allowed to electrophorese by supplying $70 \mathrm{~V}$ of power.

\subsection{Affinity Chromatography}

Affinity chromatography was performed using divinyl sulphone (DVS) activation method. The agarose column was coupled with bacterial antigen. Once this was prepared, IgY specific to antigen was added. This was collected as flow through (FT). Later five columns of PBS neutralization buffer were added. This was collected as wash fractions (WF). Finally two volumes of elution buffer were added to the column. The eluate was collected in $1.5 \mathrm{ml}$ microfuge tubes. The eluates were collected and pooled. This was later dialysed and then lyophilized.

\section{Results}

Gram staining gave a result of pink colour. Indole and Methyl Red gave positive results while VogesProskaeur and Citrate tests were negative. The Mac Conkey media test was positive. Growth curve showed that the $\log$ phase was up to $6^{\text {th }}$ hour of growth and then the stationary phase was attained. This was detected by turbidometric method (Fig. 1) and dry weight method (Fig. 2).

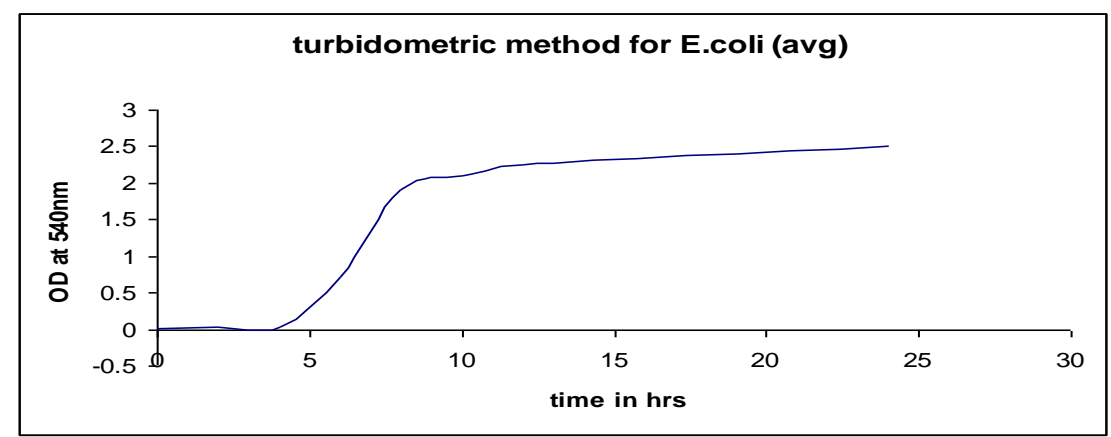

Fig. 1. Average of turbidometric method of determining the growth curve

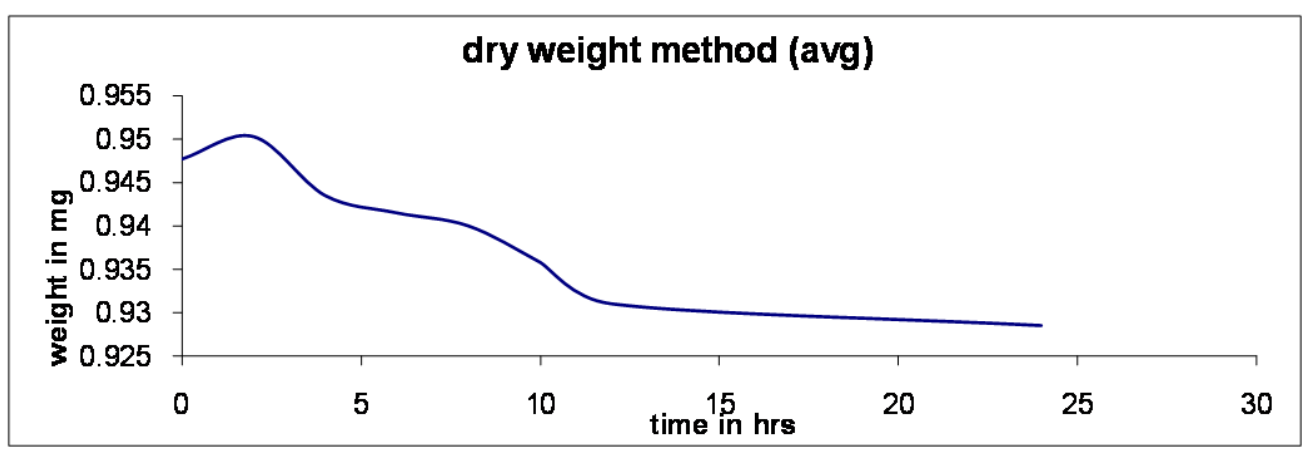

Fig. 2. Average of dry weight method 
$\mathrm{pH}$ is another factor that affects the growth of any organism. Escherichia coli O157:H7 generally grows well at the near neutral $\mathrm{pH}$ of 7.2. After the overnight growth, it showed that $\mathrm{pH} 4.5$ is where the growth begins and growth is seen upto $\mathrm{pH} 8$ (Figs. 3,4,5).

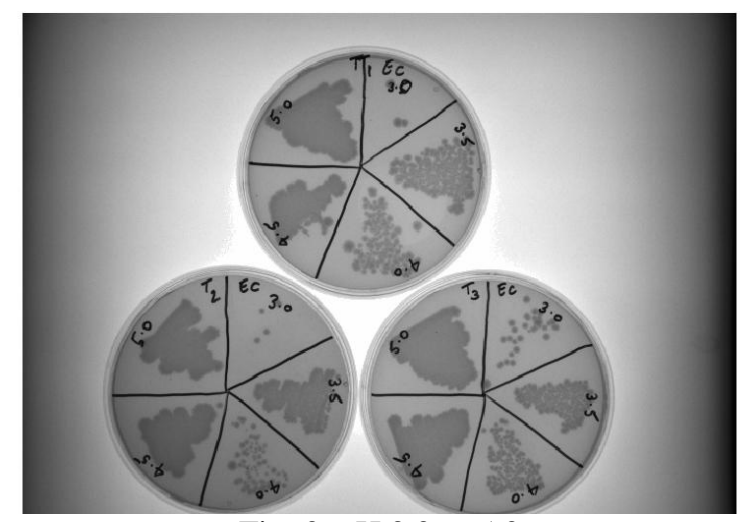

Fig. 3. pH 3.0 to 5.0

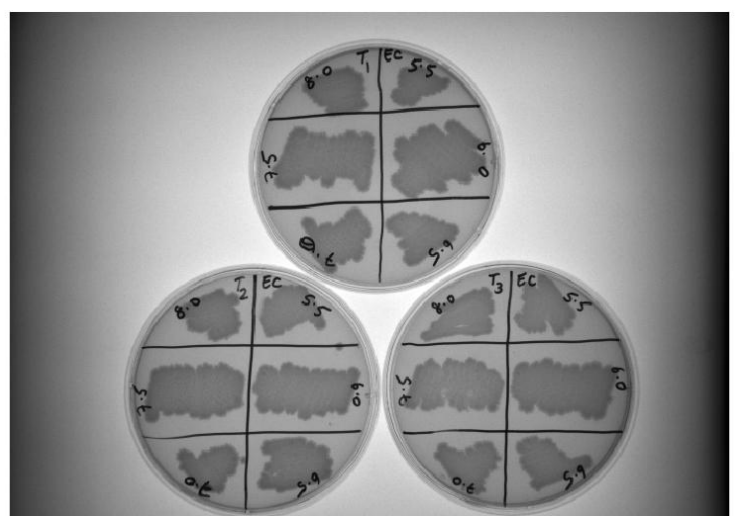

Fig. 4. pH 5.5 to 8.0

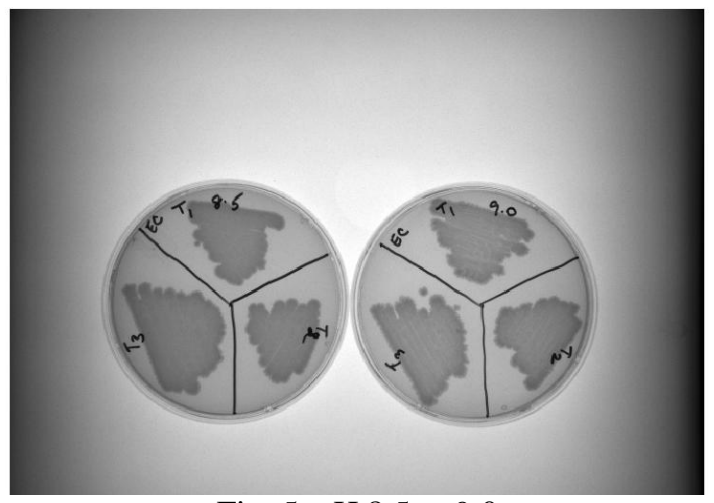

Fig. 5. pH 8.5 to 9.0

Like $\mathrm{pH}$, temperature is another important factor. Experiment for this was conducted which gave the idea as to which is the best temperature for the growth of Escherichia coli O157:H7. The result showed that between the temperature range of $37^{\circ} \mathrm{C}$ and $55^{\circ} \mathrm{C}$, the growth was at its peak (Fig. 6, 7).

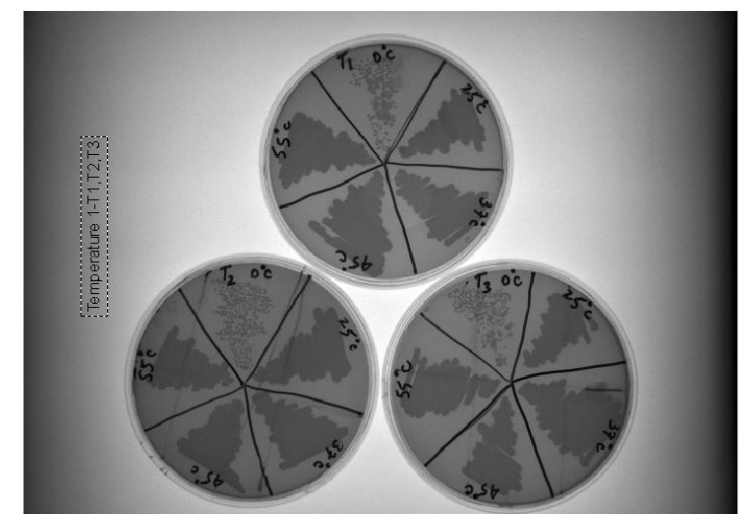

Fig. 6. Temperature $0^{\circ} \mathrm{C}$ to $55^{\circ} \mathrm{C}$

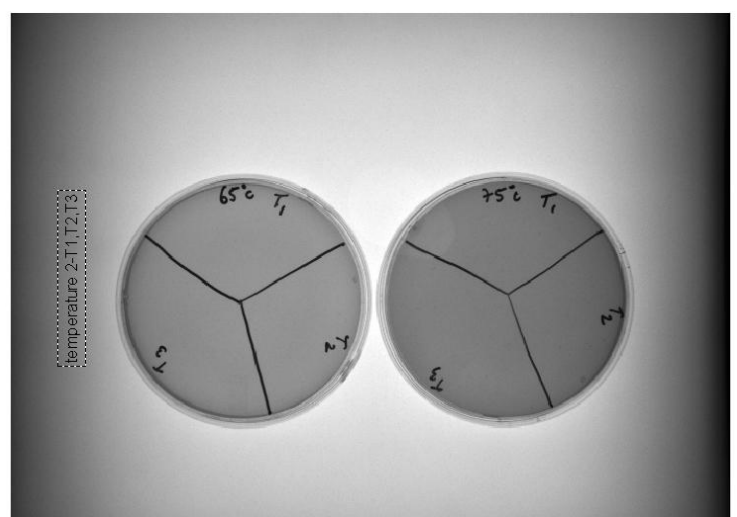

Fig. 7. Temperature $65^{\circ} \mathrm{C}$ and $75^{\circ} \mathrm{C}$

The study was for media done to decide which media gave the best results so that it can be used for all further purposes. After the overnight growth of the organism in different media mentioned in the protocol, it was determined that the TSB (autoclaved once) media was best when compared to all the other media.

The experiment was done for antibiotics was done to know how the organism will react to the antibiotics. The result showed that there was inhibition zone around oxycillin $(10 \mu \mathrm{g})$, but not around the ampicillin $(1 \mu \mathrm{g})$. 


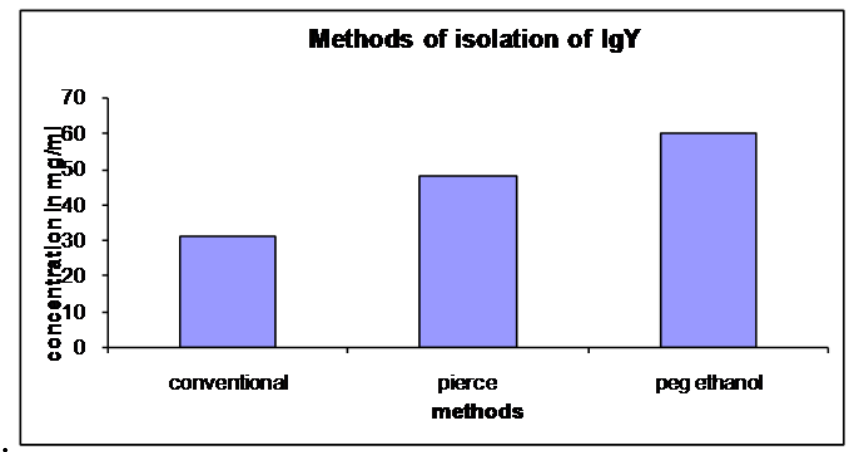

Fig. 8. Concentrations of IgY isolated from different methods

The antigen was prepared as described in the protocol. Isolation of $\operatorname{IgY}$ was done according to the above mentioned all three methods. The results showed that the yield of IgY was highest in the PEG ethanol method (Fig. 8). These results were based on the standard graph that was plotted by using Bovine Serum Albumin (BSA) (2mg/ml stock). This was done by Lowry's method.

Followed by this estimation dot blotting was done. When the strip was examined, it was seen that the undiluted antibody gave very dark colour, which indicated that the reaction was very specific. As the spots of the dilutions were observed, there was a gradual decrease in the intensity of the colour of the spots (Fig. 9).

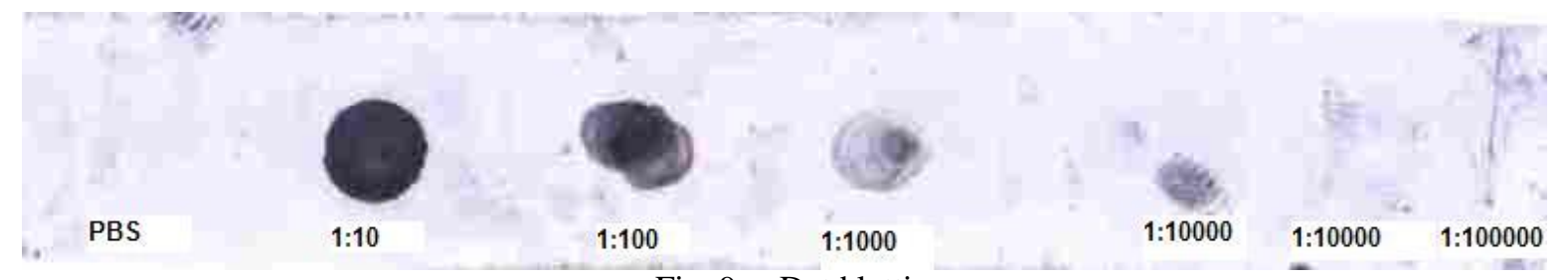

Fig. 9. - Dot blotting

After the dot blotting test, ELISA was performed to see if the results of both dot blotting and ELISA coincided. The samples tested were undiluted IgY, diluted IgY (from 1:1 to 1:1000) and a negative control. All reactions were done on a flat bottomed 96-well microtitre plate (Fig. 10). Undiluted antibody indicated intense colour when read in an ELISA reader. The intensity of the colour reduced as the dilutions increased. Negative control showed no colour.

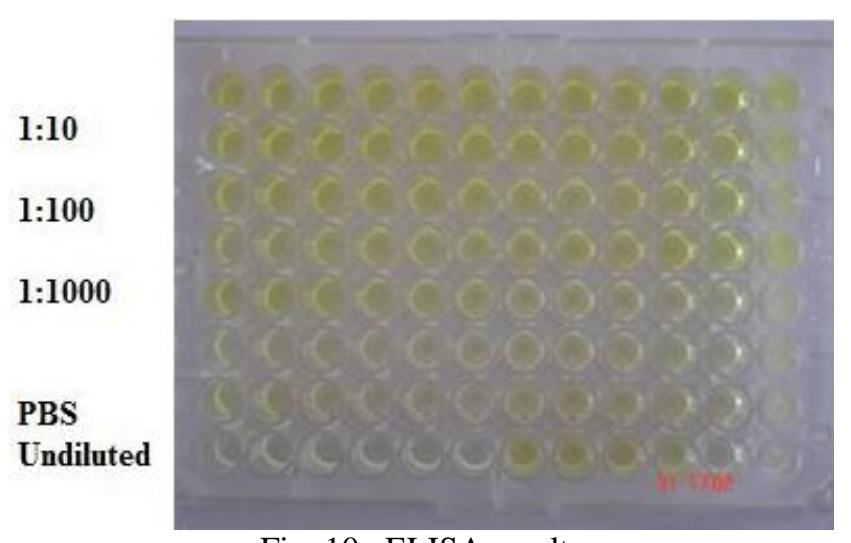

Fig. 10. ELISA results

To confirm these results SDS-PAGE was performed. IgY samples from all the three methods were run on the precast gel (Biorad cat.no. 456-1046). It was found that among the three the best result was shown by the IgY sample isolated from the PEG ethanol method (Fig. 11). 


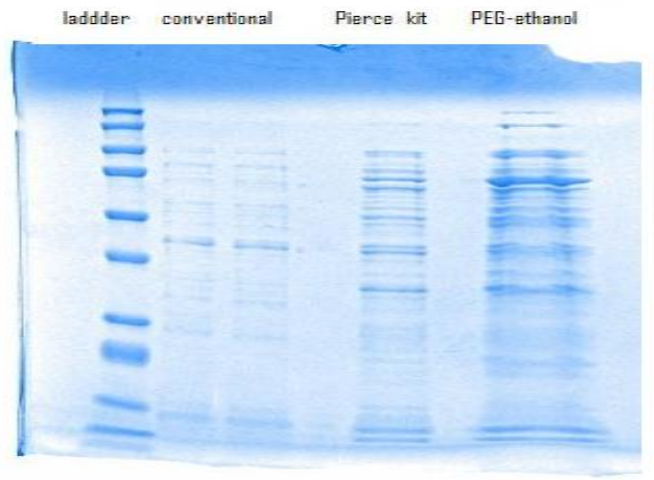

Fig. 11. SDS-PAGE for IgY from three different methods of isolation

The IgY obtained from the PEG ethanol method underwent affinity chromatography. All the eluates were later pooled. It was then dialysed and it was lyophilised. The calculation of concentrations of these were again based on Lowry's method (Table 1).

\begin{tabular}{ll}
\hline \multicolumn{1}{c}{ Samples } & \multicolumn{1}{c}{ Protein conc. $(\mu \mathrm{g} / \mathrm{ml})$} \\
\hline Pooled after isolation & 355 \\
\hline Dialysed & 445 \\
\hline After lyophilisation & 558.75 \\
\hline
\end{tabular}

\section{Discussion}

Gram staining test confirmed that Escherichia coli O157:H7 is Gram negative. Escherichia coli O157:H7 falls under the Gram negative category because of the presence of more lipids in Escherichia coli $\mathrm{O} 157: \mathrm{H} 7$ that the alcohol digests due to which pores are formed. Hence when the counter stain safranine is added, the bacterium takes it up and gives the pink colour. This is one of the most important discovery in microbiology which has been proved time and again [11]. Biochemical test includes test for presence of Indole, Methyl Red test, Voges-Proskauer test and test for presence of citrate, shortly called as IMViC test. The result that was seen in this experiment is a well known fact and has been proved several times before $[12,13,14,15$, and 16]. Growth curve showed a perfect sigmoid curve, especially in the turbidometric method, which made it easy for the determination of starting of the log phase. There was a thick lawn of Escherichia coli O157:H7 on the Mac Conkey agar plate. This is a media that is useful in differentiating Escherichia coli O157:H7 from other Escherichia coli [17, 18].

It is important to know that from which $\mathrm{pH}$ range the growth of the organism begins and similarly at which $\mathrm{pH}$ range the growth ceases completely. $\mathrm{pH} 7.2$ is where the Escherichia coli $\mathrm{O} 157: \mathrm{H} 7$ grows at its best. However despite this test it became difficult to count the individual colonies as the organism had grown into thick lawn and hence their exact number could not be found except for the extreme $\mathrm{pH}$ values.

Along with $\mathrm{pH}$, temperature is another factor that affects the growth of the organism. A fact must be noted here that the growth of the organism was seen even at $0^{\circ} \mathrm{C}$. This was no false positive result as this result was same in all the three plates. Hence an important fact that must be noted here is that, this is the reason why the glycerol stock is stored at $-80^{\circ} \mathrm{C}$. This is because the glycerol stock is always meant for further use and will be expected to be intact at the stationary phase and also be uncontaminated.

Media also plays a very important role in the growth of the organism. The conclusion obtained was after determining the turbidity of each of the culture in every media mentioned in materials and methods. The reason for TSB (autoclaved twice) not showing good results is that the contents were caramalised due to autoclaving twice. This means that all the nutrients will not be available for the organism to grow in its normal way.

The antibiotic test reveals that oxycillin is able to act against the Escherichia coli O157:H7, although not to the expected extent. However ampicillin completely failed in its action against Escherichia coli O157:H7. Once the antibody is produced there is a need to test its concentration. Antibody being a protein, the concentration of the protein can be determined by Lowry's method, which is one of the major methods for determining the protein concentration [19]. Protein concentration of not just the isolated $\operatorname{IgY}$, but the dialysed 
IgY and lyophilised IgY were also determined using the same standard curve obtained from the Lowry's method. But determining just the protein concentration is not sufficient to come to a conclusion that the production of antibody is successful. This goes through further tests of dot blotting, ELISA and finally SDSPAGE.

The colour seen on the nitrocellulose membrane in the dot blotting test was clear indication that the reaction was successful between the antigen and antibody from 1:1 to 1:1000 dilutions. The reaction of 1:10,000 was not very clear. It could not be deduced that the reaction was successful or not. However dot blot will only give a very vague idea about the reaction between the antigen and antibody. To confirm these results, ELISA was necessary. Looking at the intensity of the colour on the dot blot test, dilutions only up to 1:1000 were considered for ELISA test. The same results seen in dot blot were seen when ELISA was performed on the considered dilutions.

The final test that was done was SDS-PAGE, where it was very evident that the IgY isolated from the PEG-ethanol method showed the best result, which were bright and clear bands.

Eluates are the fractions which have antibodies. Antibody being protein can be detected either by Lowry's method or Bradford method. Here Lowry's method [19] was used. One reading was taken after pooling all the eluates from their tubes. Dialysis was performed to concentrate the antibody. This will remove the unwanted liquid matter and retain only the antibody of interest. It was finally lyophilized to get the antibody in powder form so that it can be stored for a longer time. Lyophilisation makes it even more concentrated. Protein estimation was done at all the three levels. It is clearly evident in Table 1 that concentration of antibody has drastically increased from one step to the next.

\section{Conclusions}

This study mainly gave the results of the biochemical tests and results of other important factors like $\mathrm{pH}$, temperature, media and antibiotics, which confirmed that the organism under study was Escherichia coli O157:H7 and also was pure and uncontaminated. When it comes to production of the antibodies, it is very important that it is produced in large amount and also in an easy method. Hence chicken is used for this purpose, as it not only produces large amounts of antibody, but also makes it easy for its isolation. The comparative study of isolating $\operatorname{IgY}$ made between three methods, conventional type, using Pierce kit and PEG ethanol method gave the results which decided that the quality and yield of the IgY isolated from PEG ethanol method was the best among all the three methods used.

\section{References}

[1] Sheng H, Lim JY, Watkins KM, Minnich SA and Hovde JC Characterization of an Escherichia coli O157:H7 O-Antigen Deletion Mutant and Effect of the Deletion on Bacterial Persistence in the Mouse Intestine and Colonization at the Bovine Terminal Rectal Mucosa, Applied And Environmental Microbiology 2008;74:16:5015-5022.

[2] Wani S, Pandit F, Samanta I, Bhat MA and Buchh AS.. Molecular epidemiology of Shiga toxinproducing Escherichia coli in India, Current Science 25 November, 2004;87:10:1345-1353.

[3] He Y, Keen JE, Westerman RB, Littledike ET and Kwang J. Monoclonal Antibodies for Detection of the H7 Antigen of Escherichia coli. Applied And Environmental Microbiology Sept 1996; 62:9:3325-3332.

[4] Dhanashree B and Mallya PS. Detection of shiga-toxigenic Escherichia coli (STEC) in diarrhoeagenic stool \& meat samples in Mangalore, India, Indian J Med Res September 2008;128:271-277.

[5] Peters H, Jurs M, Jann B, Jann K, Timmis KN and Bitter-Suermann D. Monoclonal Antibodies to Enterobacterial Common Antigen and to Escherichia coli Lipopolysaccharide Outer Core: Demonstration of an Antigenic Determinant Shared by Enterobacterial Common Antigen and E. coli K5 Capsular Polysaccharide, Infection and Immunity 1985;50:2:459-466.

[6] Sheoran AS, Bonofiglio SC, Harvey BR, Mukherjee J, Georgiou G, Donohue-Rolfe A, and Tzipori S. 2005. Human Antibody against Shiga Toxin 2 Administered to Piglets after the Onset of Diarrhea Due to Escherichia coli O157:H7 Prevents Fatal Systemic Complications, Infection And Immunity 2005; 73:8: 4607-4613.

[7] Li X, Nakano T, Sunwoo HH, Paek BH, Chae HS, and Sim JS. Effects of Egg and Yolk Weights on Yolk Antibody (IgY) Production in Laying Chickens, Poultry Science 1998;77:266-270.

[8] Ko KY and Ahn DU. Preparation of Immunoglobulin Y from Egg Yolk Using Ammonium Sulfate Precipitation and Ion Exchange Chromatography, Poultry Science 2007;86:400-407.

[9] Hatta H, Kim M, and Yamamoto T. A Novel Isolation Method for Hen Egg Yolk Antibody, "IgY", Agric. Biol Chem 1990;54(10):2531-2535.

[10] Scopes, K. R. 2004. Protein Purification and Practice, third Edition, Chapter 7, p206-210.

[11] Bartholomew JW and Mittwer T. The Gram Stain, Bacteriol Rev. March 1952:16(1): 1-29.

[12] Clark WM, and Lubs HA. Improved Chemical Methods For Differentiating Bacteria Of The Coli-Aerogenes Family. J. Inf. Dis 1915:17:1660-1673.

[13] Forbes BA, Sahm DF and Weissfeld, AS. Baily and Scott's Diagnostic Microbiology, 11 ${ }^{\text {th }}$ edition 2002:152-153.

[14] Koser SA. Utilization of the salts of organic acids by colon-aerogens group. J. Bacteriol. 1923;8:493-520.

[15] MacFaddin JF. Biochemical Tests for Identification of Medical Bacteria. Williams \& Wilkins, $1980: 173$ - 183.

[16] Simmons JS. A culure medium for differentiating the organism of the typhoid -colon-aerogenes groups and for isolation of certain fungi. J. Infect. Dis. 1926;39:209-214.

[17] MacConkey AT. Lactose-Fermenting Bacteria in Faeces, J Hyg (Lond) 1905;5(3): 333-379.

[18] MacConkey AT. Bile Salt Media and their advantages in some Bacteriological Examinations, J Hyg (Lond) 1908;8(3): $322-334$.

[19] Lowry OH, Rosebrough NJ, Farr AL and Randall RJ. Protein Measurement with Folin-Phenol Reagent, J.Biol.Chem $1951 ; 193: 265-275$ 